\title{
A new pathway in the control of the initiation of puberty: the MKRN3 gene
}

\author{
Ana Paula Abreu, Delanie B Macedo', Vinicius N Brito', Ursula B Kaiser and \\ Ana Claudia Latronico'
}

Division of Endocrinology, Diabetes and Hypertension, Harvard Medical School, Brigham and Women's Hospital, Boston, Massachusetts, USA

${ }^{1}$ Unidade de Endocrinologia do Desenvolvimento, Disciplina de Endocrinologia e Metabologia, Laboratório de Hormônios e Genética Molecular, LIM 42, Hospital das Clínicas, Faculdade de Medicina da Universidade de São Paulo, Avenida Dr Enéas de Carvalho Aguiar, 255, $7^{\circ}$ andar, sala 7037, CEP: 05403-900, São Paulo, Brazil

Correspondence should be addressed to A C Latronico Email anacl@usp.br

\begin{abstract}
Pubertal timing is influenced by complex interactions among genetic, nutritional, environmental, and socioeconomic factors. The role of $M K R N 3$, an imprinted gene located in the Prader-Willi syndrome critical region (chromosome 15q11-13), in pubertal initiation was first described in 2013 after the identification of deleterious MKRN3 mutations in five families with central precocious puberty (CPP) using whole-exome sequencing analysis.

Since then, additional loss-of-function mutations of MKRN3 have been associated with the inherited premature sexual development phenotype in girls and boys from different ethnic groups. In all of these families, segregation analysis clearly demonstrated autosomal dominant inheritance with complete penetrance, but with exclusive paternal transmission, consistent with the monoallelic expression of MKRN3 (a maternally imprinted gene). Interestingly, the hypothalamic Mkrn3 mRNA expression pattern in mice correlated with a putative inhibitory input on puberty initiation. Indeed, the initiation of puberty depends on a decrease in factors that inhibit the release of GnRH combined with an increase in stimulatory factors. These recent human and animal findings suggest that MKRN3 plays an inhibitory role in the reproductive axis to represent a new pathway in pubertal regulation.
\end{abstract}
Key Words
- hypothalamus and neuroendocrinology
- gonadotropins
- mutations
- secretion

Journal of Molecular Endocrinology (2015) 54, R131-R139

\section{Introduction}

Puberty, a complex biological process involving sexual maturation and accelerated linear growth, is initiated when the pulsatile secretion of gonadotropin-releasing hormone $(\mathrm{GnRH})$ increases after a quiescent period during childhood. The regulation of puberty initiation remains as one of the great mysteries of human biology and it is thought that a conjunction of factors plays a role to initiate puberty.

Environmental and metabolic factors are important regulators of pubertal development, but these influences are superimposed upon substantial genetic control. Similar timing of puberty shared by mothers and her children, and within racial groups, suggests a genetic component to the onset of puberty (Zacharias \& Wurtman 1969, Herman-Giddens et al. 1997). Substantial efforts have been made to identify genes that are responsible for the initiation of puberty (Ojeda \& Lomniczi 2014). The identification of these genes is critical for advancing the understanding of the neuroendocrine regulation of puberty initiation.

Published by Bioscientifica Ltd 
In an attempt to identify genes operating within the neuroendocrine brain that ultimately regulate the reproductive axis, researchers have been studying patients with pubertal disorders. The hypothalamic-pituitary-gonadal axis regulates puberty initiation and reproduction. GnRH is produced and secreted by the hypothalamus in a pulsatile manner during the embryonic and neonatal phases of life. GnRH secretion is actively inhibited during infancy and puberty begins with the reactivation of its secretion. GnRH deficiency results in hypogonadotropic hypogonadism, in which patients fail to develop puberty and are usually infertile. Conversely, early reactivation of GnRH secretion results in central precocious puberty (CPP). While several genes have been detected in association with GnRH deficiency and have contributed to the current knowledge of GnRH regulation (Bianco \& Kaiser 2009, Semple \& Topaloglu 2010), genes linked to CPP have until recently only been identified subsequent to their association with hypogonadotropic hypogonadism, such as KISS1 and KISS1R. However, only rare genetic defects in KISS1 and its receptor have been identified in patients with CPP (Teles et al. 2008, Silveira et al. 2010).

The advances in sequencing methods permitted the detection of new genes implicated in the neuroendocrine regulation of puberty. Using exome sequencing analysis and studying familial cases of CPP, genetic defects in a gene with no previous link to the hypothalamic-pituitarygonadal axis, Makorin ring finger 3 (MKRN3), were identified as the cause of premature sexual development in one-third of the families (Abreu et al. 2013). MKRN3 is located on the long arm of chromosome 15 in the
Prader-Willi syndrome (PWS) critical region and is maternally imprinted (discussed later). Subsequently, we showed that mutations in MKRN3 are also the cause of CPP in apparently sporadic cases (Macedo et al. 2014). These findings were significant contributions to the field and will advance the understanding of the pubertal process. We will review the genetic defects identified in patients with CPP and their clinical implications, and discuss herein the possible role of MKRN3 within the reproductive axis.

\section{Loss-of-function mutations of MKRN3 cause familial CPP}

The role of $M K R N 3$ in pubertal initiation was first described in 2013 after a comprehensive genetic study of several families with CPP (Abreu et al. 2013). In this study, the authors investigated 40 members of 15 families with CPP from different ethnic groups (12 Brazilian, two American, and one Belgian families), and applying whole-exome sequencing four deleterious MKRN3 mutations - three frameshift and a missense mutation (Fig. 1) - were detected in five of these families (33\%). Both sexes were equally affected by MKRN3 mutations (eight girls and seven boys) (Table 1).

More recently, Macedo et al. (2014) studied 215 unrelated children (207 girls and eight boys) with CPP from three different University Medical Centers and identified five novel heterozygous mutations in eight unrelated Brazilian girls, including four frameshift variants and one missense variant (Fig. 1 and Table 1). No family history of premature sexual development was

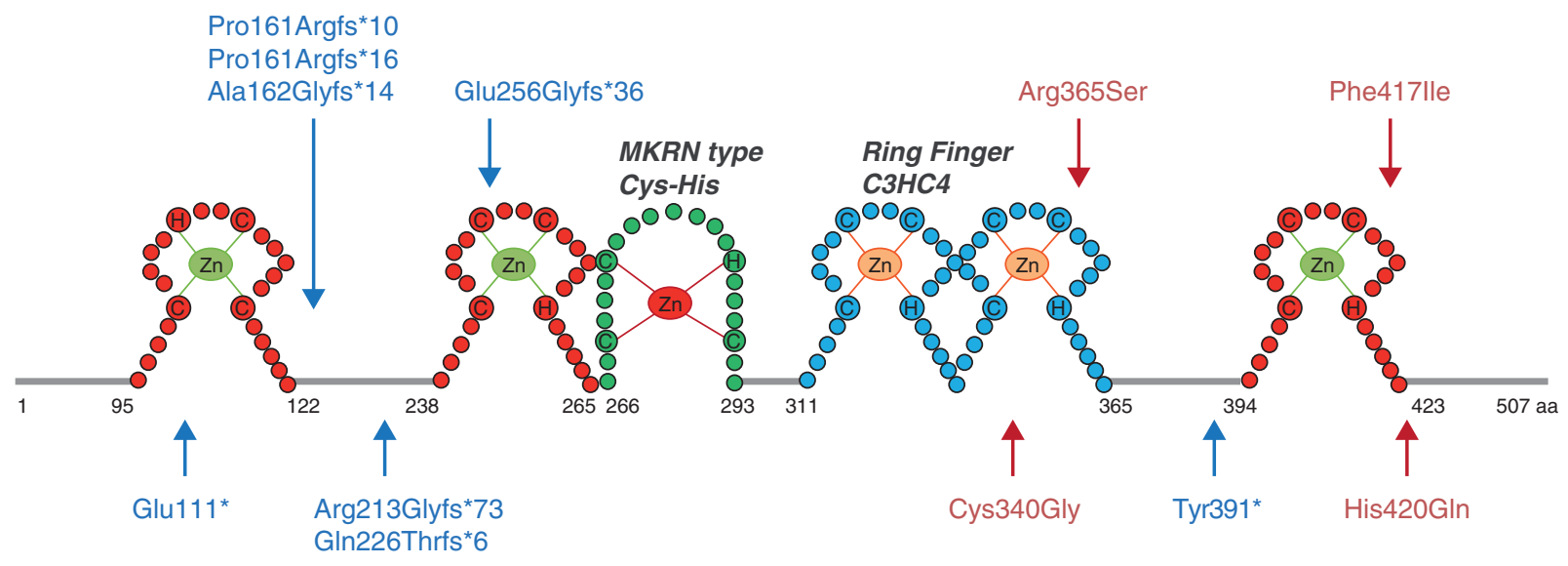

Figure 1

MKRN3 protein structure and mutations identified in patients with central precocious puberty. $\mathrm{Zn}$, zinc; $\mathrm{H}$, histidine; $\mathrm{C}$, cysteine. The three $\mathrm{C} 3 \mathrm{H}$ zinc finger motifs are shown in red, the C3HC4 RING finger motif is in blue, and the MKRN-specific Cys-His domain is shown in green. The numbers correspond to the amino acid positions in the protein. Blue mutation labels and arrows indicate the location of frameshift mutations; red mutation labels and arrows indicate the location of the missense mutations. 


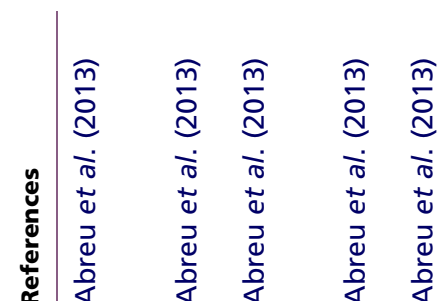

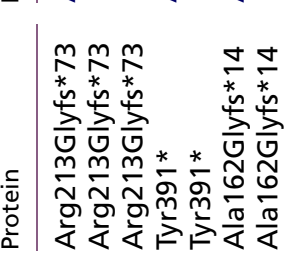

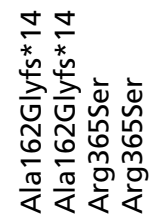
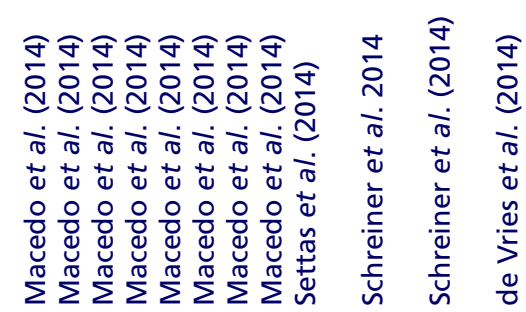

운

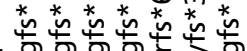

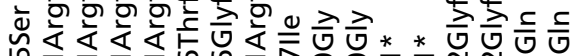

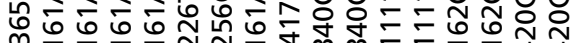

m는 는

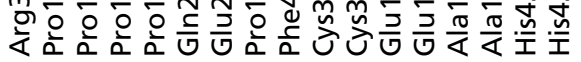

状商

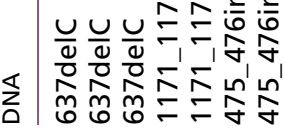

品

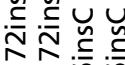

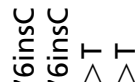

$\dot{q} \hat{y} \hat{0}$

ํํㄴํํㅇㅇㅇㅇ

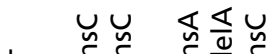

ư

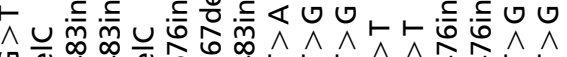

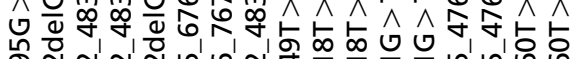

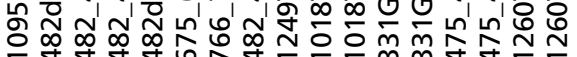

৩

$\wedge \wedge$

웡ㅇㅇ

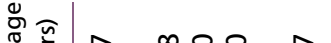

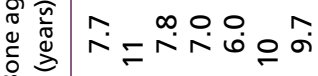

$=\infty \stackrel{m}{\circ} \stackrel{0}{\sim}$

L $\infty \quad \infty \quad \infty m \infty$

$\stackrel{\infty}{6}=$

$\stackrel{\infty}{\infty} \stackrel{0}{0}$

$\sim m \sim m m m$

$m \sim \sim m$

$\sim m m \forall m \forall m m m m \sim m m \mid \sim m m$

$m \sim$

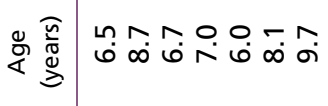

$\infty \ln \nabla n$

ก $\infty-a n \infty 60--0$

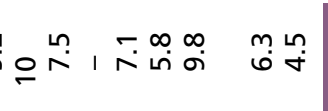

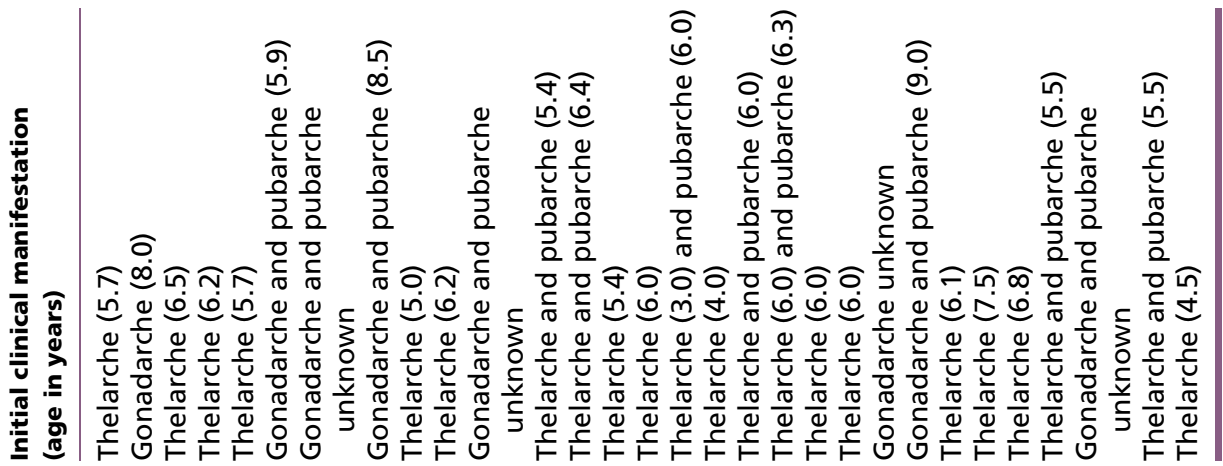

$$
\text { ڤั㐅े }
$$

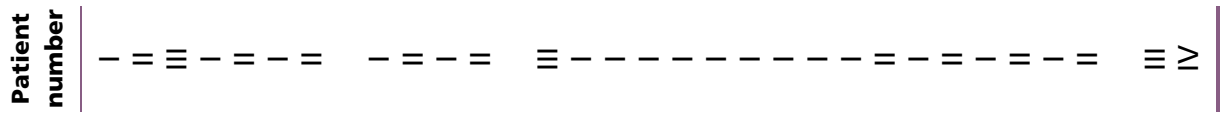

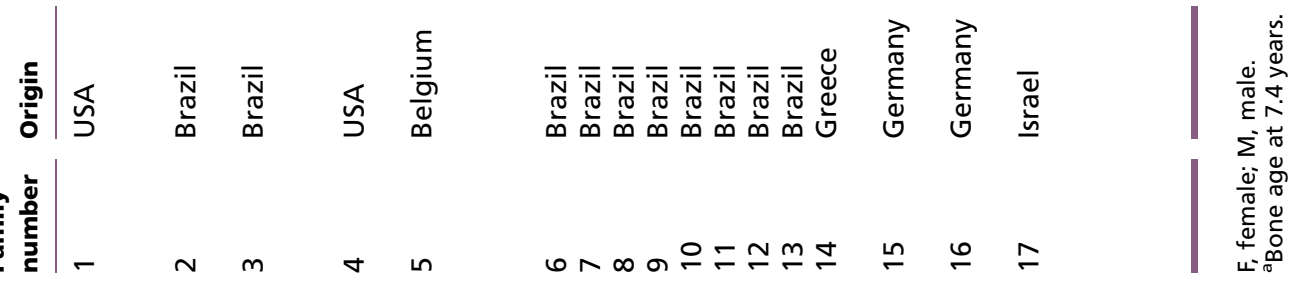


reported in the majority of these studied patients. However, segregation analysis was performed for five of these eight girls, and in all cases it has been demonstrated that the mutant allele was paternally inherited in all families with MKRN3 mutations.

In order to investigate whether the CPP phenotype could arise from loss of MKRN3 expression by the paternal allele due to a de novo deletion, maternal uniparental disomy, or an imprinting defect, Macedo et al. (2014) investigated 52 patients with familial and sporadic CPP, without known MKRN3 sequence defects, by methylationspecific multiplex ligation-dependent probe amplification (MS-MLPA) of chromosome 15q11. No copy number changes or methylation abnormalities were detected in the $15 \mathrm{q} 11$ locus, suggesting that epigenetic defects involving this locus are likely rare mechanisms in this disorder (Macedo et al. 2014).

Recently, other investigators have also reported MKRN3 defects associated with familial CPP. Settas et al. (2014) described a novel heterozygous missense mutation (p.Cys340Gly) in MKRN3 in two Greek siblings, a girl with CPP and a boy with early puberty. Soon thereafter, Schreiner et al. (2014) identified two heterozygous MKRN3 mutations (p.Glu111* and p.Ala162Glyfs*14) in affected members of two German families. Finally, de Vries et al. (2014) identified a novel missense mutation (p.His420Gln) in four siblings, including a boy, from an Ashkenazi-Sephardic Jewish family (Fig. 1 and Table 1). These studies further expanded the MKRN3 mutational spectrum.

\section{Clinical features of CPP associated with MKRN3 mutations}

All patients with CPP carrying loss-of-function mutations in MKRN3 exhibited typical clinical and hormonal features of premature activation of the reproductive axis, including early pubertal signs, such as breast, testes, and pubic hair development, accelerated linear growth, advanced bone age, and elevated basal and/or GnRHstimulated LH levels (Table 1). Except for two related patients (one girl and her brother) who presented with esotropia (Abreu et al. 2013), which is a minor criterion for PWS, no other signs of PWS were detected in any patient with CPP caused by MKRN3 defects. Another female patient had mild nonspecific syndromic features, including a high-arched palate, dental abnormalities, clinodactyly, and hyperlordosis (Macedo et al. 2014). Regarding the therapeutic response of CPP patients with MKRN3 defects, six of eight patients have demonstrated adequate responses to conventional treatment with depot GnRH agonists to date (Macedo et al. 2014).

In patients with CPP due to MKRN3 defects, the median age of puberty onset was 6.0 years in girls (ranging from 3.0 to 7.5 years) and 8.25 years in boys (ranging from 5.9 to 9.0 years) (Abreu et al. 2013, Macedo et al. 2014, Schreiner et al. 2014, Settas et al. 2014, de Vries et al. 2014), suggesting that the MKRN3 mutations may affect girls more severely than boys (Table 1). Given the median age of pubertal onset of affected patients with MKRN3 mutations, it is speculated that the prepubertal inhibitory tonus on GnRH secretion took place normally, but was lost prematurely in patients with MKRN3 mutations. This clinical observation suggests that MKRN3 may not be crucial for GnRH suppression after the mini-puberty of early infancy, but that the downregulation of MKRN3 plays a relevant role for the re-emergence of GnRH pulses in the pubertal onset (Macedo et al. 2014).

\section{MKRN3 mutations and polymorphisms}

Currently, 12 distinct loss-of-function mutations of MKRN3 have been described in 30 patients (22 girls and eight boys) with CPP from 17 families from different ethnicities (Fig. 1 and Table 1). Remarkably, eight of these mutations encode either premature stop codons or frameshift mutations (Table 1). The four missense mutations (p.Cys340Gly, p.Arg365Ser, p.Phe417Ile, and p.His420Gln) were located within a zinc finger motif or a RING finger motif (Fig. 1), regions predicted to be involved in RNA binding and ubiquitin ligase activity of the protein respectively, and essential for protein function. All missense mutations are predicted to be pathogenic by in silico analysis. Additionally, $a b$ initio modeling of the mutations p.Arg365Ser and p.Cys340Gly predicts that these mutations lead to significant structural perturbations in the 3D structure of the RING finger motif (Settas et al. 2014). The substitution of histidine 420 with glutamine in the MKRN3 protein is predicted to reduce the affinity between the $\mathrm{Zn}$ ion-binding site and the relevant $\mathrm{Zn}$, disrupting the binding pocket leading to unfolding of the finger (de Vries et al. 2014). Interestingly, most of the MKRN3 mutations (64\%) were located in the amino-terminal region of the protein, which is encoded by a poly-C-rich sequence, suggesting that this area may be a potential hotspot.

The important role of MKRN3 in human puberty initiation has been reinforced recently by large genomewide and custom-genotyping arrays in up to 182416 women of European descent (57 studies) (Perry et al. 2014).

Published by Bioscientifica Ltd 
There was evidence of 123 signals at 106 genomic loci associated with age at menarche. Three of these loci were located in imprinted regions, including the MKRN3 locus, demonstrating parent-of-origin-specific associations concordant with known parental expression patterns (Perry et al. 2014). This study suggests that not only are rare variants in MKRN3 associated with CPP, but also more common variants/polymorphisms may be associated with changes in the timing of puberty (as reflected by the age of menarche) within the normal range and within the general population. This was a remarkable extension of the findings of rare variants in a disease such as CPP to more common variants in a polygenic trait such as age of menarche. The lack of parent-of-origin-specific analysis in previous GWAS studies may explain why MKRN3 has not been previously associated with the age of menarche (He et al. 2009, Elks et al. 2010).

\section{MKRN3 gene and protein structure and expression}

MKRN3 was first cloned in 1999 by Jong et al. (1999a) during a study of the Prader-Willi/Angelman syndrome (PW/AS) critical region. They identified a cDNA in the PW/AS region encoding a zinc finger protein, initially named zinc finger protein 127 (ZNF127) and later renamed MKRN3. The functional and physiological relevance of MKRN3 is not known and despite its location in the PWS critical region, its role in this syndrome is also unclear. An antisense transcript was concomitantly identified and named ZNF127AS (MKRN3-AS1). The antisense gene is not translated and is expressed weakly during fetal development and at very low levels in adult brain regions (Jong et al. 1999a). Similar to other antisense genes, ZNF127AS may regulate the expression of the 'sense' gene (MKRN3).

$M K R N 3$ is located on human chromosome 15q11-13 (chromosome $7 \mathrm{C}$ in mouse) in a region that contains a cluster of imprinted genes associated with two different neurobehavioral disorders (Lalande 1996, Nicholls et al. 1998). Mutations or loss of expression of the maternally expressed gene UBE3A lead to Angelman syndrome (AS), while PWS is thought to be a contiguous gene syndrome arising from the loss of expression of multiple paternally expressed genes, including MKRN3. The report of two patients with PWS with a deletion of the 15q11-13 locus that did not include MKRN3 suggested that this gene is not required for the development of the syndrome, but we still cannot rule out a role for MKRN3 in some of the clinical features of PWS (Kanber et al. 2009).
MKRN3 differential allele expression occurs through silencing of the MKRN3 maternal allele, which is associated with $5^{\prime} \mathrm{CpG}$ island methylation (Hershko et al. 1999, Jong et al. 1999b). Methylation of MKRN3 and the other imprinted genes located within the PW/AS region of chromosome 15 is coordinately regulated by a bipartite imprinting control center (IC), composed of a sequence around the SNRPN promoter, the PWS-IC, and an $880 \mathrm{bp}$ sequence located $35 \mathrm{~kb}$ upstream, the AS-IC (Rabinovitz et al. 2012). The molecular mechanisms of IC function are not well understood, but it has been postulated, based on studies in humans and mouse models, that the PWS-IC is a positive regulatory element and activates paternalspecific gene expression (Bielinska et al. 2000, Bressler et al. 2001), whereas the AS-IC functions in the maternal imprint by allele-specific repression of the PWS-IC to prevent the paternal imprinting program (Jong et al. 1999b, Ohta et al. 1999, Shemer et al. 2000, Rodriguez-Jato et al. 2005).

$M K R N 3$ is an intronless gene, and probably arose by germline retrotransposition from the Makorin ring finger protein 1 gene (MKRN1), a highly transcribed, introncontaining gene, 80-90 million years ago (Rapkins et al. 2006). MKRN1 is the ancestral founder of the Makorin gene family (Gray et al. 2000). Several other retrocopies of MKRN1 have been identified in mammalian genomes, most of them probably corresponding to pseudogenes. Nine MKRN family loci distributed throughout the human genome have been identified thus far, with only three functional genes - MKRN1, MKRN2, and MKRN3 - identified in vertebrates (Gray et al. 2000, Bohne et al. 2010).

\section{The MAKORIN family}

The MKRN gene family encodes putative ribonucleoproteins with a distinctive array of zinc-finger motifs including several $\mathrm{C} 3 \mathrm{H}$ zinc fingers, a makorin-specific Cys-His arrangement, and a RING zinc finger (Jong et al. $1999 a, b)$. In particular, MKRN3 has a centrally located RING finger motif (C3HC4), two amino-terminal C3H zinc finger motifs followed by the unique pattern of conserved Cys-His residues called a Makorin zinc finger motif, and a carboxy-terminal C3H zinc finger motif (Jong et al. 1999a; Fig. 1). MKRN3 is highly conserved among species, and the mouse and human MKRN3 amino acid sequences share $69 \%$ identity and $82 \%$ similarity (Jong et al. 1999a). Mice and humans usually do not have conserved UTRs, yet the MKRN3 3'-UTR has 90\% identity between these two species, implying a functional significance to this region of MKRN3. MKRN3 is ubiquitously expressed in

Published by Bioscientifica Ltd. 
adult human tissue, with the highest expression levels in the testis. In the fetus, it is highly expressed in the CNS and is expressed in post-meiotic sperm germ cells, particularly in round spermatids (Jong et al. 1999a).

The characteristic arrangement of cysteine (Cys or C) and histidine (His or $\mathrm{H}$ ) residues in the zinc finger proteins in MKRN3 can allow some predictions of its function. C3H zinc fingers have been identified in RNA-binding proteins (Barabino et al. 1997, Murray et al. 1997). RING zinc fingers have been shown to mediate protein:protein interactions (Schwabe \& Klug 1994). More recent evidence suggests that the RING zinc finger is a signature domain for E3 ligases, a category of enzymes mediating the transfer of ubiquitin from an E2 ubiquitin-conjugating enzyme to target protein substrates (Deshaies \& Joazeiro 2009). Ubiquitination can have diverse effects on the protein substrate, varying from proteasome-dependent proteolysis to modulation of protein function and/or localization (Deshaies \& Joazeiro 2009, Behrends \& Harper 2011). The multiple types and number of zinc finger motifs in makorin proteins suggest possible multiple cellular functions for this protein.

Makorin proteins share a highly homologous amino acid sequence, particularly in the zinc finger domains (Fig. 2), suggesting that they may share similar functions or regulatory mechanisms. Although there are not many studies on MKRN3 function to date, MKRN1 function has been better explored. A possible important cellular function for MKRN1 is supported by the high identity (92\%) between the human and murine orthologs and the ubiquitous protein expression in human and mouse tissues (Gray et al. 2000). MKRN1 acts as an E3 ubiquitin ligase, inducing degradation of human telomerase reverse transcriptase (hTERT), viral capsid proteins, p53 and p21 cell cycle regulators, and peroxisome proliferatoractivated receptor gamma (PPAR $\gamma$ ) (Kim et al. 2005, 2014, Lee et al. 2009).

An alternative mechanism of action for MKRN1 was described when it was identified as a repressor of c-Jun transcriptional activity using a yeast assay. Through regulation of RNA polymerase II-dependent transcription, MKRN1 can have either negative or positive effects on gene expression (Omwancha et al. 2006). Interestingly, it has been demonstrated that the disruption of ubiquitin ligase activity of MKRN1 did not affect its inhibitory transcriptional activity, suggesting that this function is independent of protein ubiquitination (Omwancha et al. 2006).

MKRN2 is also ubiquitously expressed (Gray et al. 2000). Similar to other members of this family, MKRN2 is highly conserved throughout evolution. It has been shown that mkrn2 negatively regulates neurogenesis via PI3K/Akt signaling in Xenopus embryos; however, the detailed molecular mechanisms of this effect and the potential functions of mammalian MKRN2 remain yet to be studied (Yang et al. 2008).

MKRN3 presumptively possesses ubiquitin-protein isopeptide ligase (E3) activity, intimated by the presence of the highly conserved C3HC4 RING finger domain. The tandem repeat of $\mathrm{C} 3 \mathrm{H}$ zinc fingers may provide

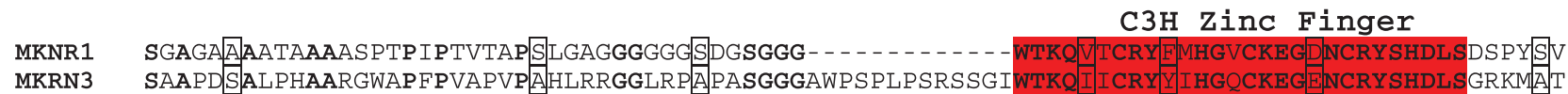 \\ MKNR1 VCKYFQRGYCIYGDRCRYEHSRPLKQEEATATELTTKSSLAASSSLSSIVGPLVEMNTGEAESRNSN-FATVGAGSEDWVNAIEFVPG MKNR3 EGGVSPPGASAGGGPSTAAHIEPPTQEVAEAPP - - - - - AASSLSLPVIGSAAERGFFEAERDNADRGAAGGAGVESWADAIEFVPG \\ C3H Zinc Finger \\ MKNR1 QPYCGRTAPSCTEAPLQGSVTKEESE KEQTAVE MKNR3 QPYRGRWVASAPEAPLQSS - - -ETERKQMAV \\ MKNR1 MKNR3 \\ C3HC4 RING EKDMELSFAVQRSKDMVCGICMEVVYEKANP SERRFGILSNCNHTYCLKCIRKWRSAKQFE SKI IKSCPECRITSNFVIPSEYWVEE K EKDMELSFAVQRGMDKVCGICMEVVYEKANPNDRRFGILSNCNH SF C IRCIRRWRSARQFENRIVKSCPQCRVTSELVIPSEFWVEE E C3H zinc Finger \\ MKNR1 MKNR3 \\ MKRN type $\mathrm{CH}$ CDMCGLQVLHPMDAAQRSQHIKS CIEAH CDMCGLQVLHPMDAAQRSQHIKS CIEAH
CDMCGLQTLHPMDAAQREEHMRA CIEAH DGRREEPQRQKVGTSSRYRAQRRNHFWELTEERENSNP FDND EEEV EGWGDEPPGPGGGSF SAYWHQ - - - LVEPVRMGEGNMLYYKSI KKE}

\section{Figure 2}

MKRN1 and MKRN3 protein sequence alignment. The two protein sequences share high homology and similarity, especially in the RING finger domains. Bold letters represent conserved amino acids, and squares similar amino acids. Sections highlighted in red represent the three zinc fingers
() 2015 Society for Endocrinology Printed in Great Britain
$\mathrm{C} 3 \mathrm{H}$ motifs, in yellow the MKRN-specific Cys-His motif, and in green the RING finger domain. MKRN1 NCBI Reference Sequence NP_038474, UniProtKB/Swiss-Prot: Q9UHC7.3. MKRN3 NP_005655.1 and UniProtKB/ Swiss-Prot Q13064.1.

Published by Bioscientifica Ltd. 
high-specificity RNA binding (Hudson et al. 2004), and the unique Cys-His makorin motif has been suggested to be a DNA-binding domain. Taken together, the studies of MKRN1 and MKRN2 imply that MKRN3 can similarly act as an E3 ligase, based on the high homology of the RING finger domain (Fig. 2). A previous study on mice demonstrated that Mkrn3 is highly expressed in the hypothalamic arcuate nucleus during the infantile and early juvenile periods, with a reduction in expression at postnatal days 12-15, before puberty initiation (Abreu et al. 2013). The arcuate nucleus is the site of expression of critical regulators of GnRH secretion, such as kisspeptin, neurokinin B, and dynorphin (Navarro et al. 2011). Puberty is initiated with a loss of inhibitory inputs and a gain in excitatory inputs (Ojeda \& Lomniczi 2014). The Mkrn3 expression pattern in the hypothalamic arcuate nucleus suggests that this peptide plays a role in the inhibition of GnRH secretion during the prepubertal quiescent period (Fig. 3). The decrease in Mkrn3 expression is hypothesized to be associated with an increase in $\mathrm{GnRH}$ stimulatory factors and/or GnRH expression, and it can be postulated that MKRN3 may be acting at the hypothalamic level as an E3 ligase to inhibit stimulatory inputs, so that loss-of-function mutations of MKRN3 result in early activation of the hypothalamic-pituitary-gonadal axis, expressed phenotypically as CPP. It is also possible that MKRN3 can act as a transcriptional regulator, as has been demonstrated for MKRN1. Data from the Human Protein Atlas indicate that MKRN3 is located primarily in the plasma membrane and cytoplasm, and also in the nucleus (www.proteinatlas.org). Based on its location in

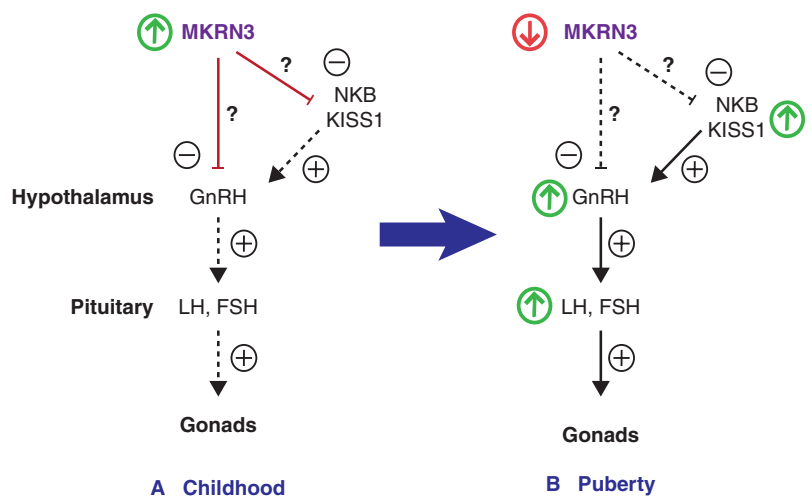

\section{Figure 3}

Schematic representation of MKRN3 mechanism of action. Human and mouse studies suggest that MKRN3 acts as an inhibitor of GnRH secretion during childhood (diagram on $\mathrm{A}$ ), and that a decrease in $M K R N 3$ expression is associated with an increase in GnRH stimulatory factors and/or GnRH resulting in puberty initiation (diagram on $B$ ). NKB, neurokinin $B_{i}$ - inhibition, + stimulation. $\uparrow$ increase $\downarrow$ decrease. the plasma membrane, we can speculate that MKRN3 may also be involved in endocytosis and downregulation of receptors, as has been demonstrated for some other E3 ligases (Hershko \& Ciechanover 1998). The genetic findings from patients with CPP are in agreement with the hypothesis that MKRN3 may act as a 'brake' or inhibitor of GnRH secretion during childhood (Hughes 2013). Further studies are needed to elucidate the precise mechanism(s) of action of MKRN3.

\section{Conclusion}

Age of puberty initiation is associated with causes of substantial morbidity and mortality. Early age of menarche is associated with breast cancer and cardiovascular disease (Kvale 1992, Lakshman et al. 2009). Therefore, it is important to understand the mechanisms controlling puberty initiation. In an attempt to identify genes that will broaden the knowledge on GnRH regulation to bring new genetic screening, and diagnostic and treatment tools, researchers have been trying to identify genes associated with CPP for several years. By studying individuals with hypogonadotropic hypogonadism, a genetic disorder caused by absence or deficiency of GnRH secretion, we learned about important stimulators of GnRH secretion (Bianco \& Kaiser 2009, Semple \& Topaloglu 2010). Owing to the complexity of the mechanisms involved in puberty initiation and the initial failure to identify genes associated with CPP, it has been hypothesized that CPP was not caused by mutations in a single gene, but rather was a consequence of complex interactions among environment, metabolic factors, and polygenic defects. However, with the development of new sequencing methodologies, the combination of wholeexome sequencing analysis with detailed phenotypic characterization and the careful selection of the correct cohort of patients led to the identification of MKRN3 as an important regulator of pubertal development. MKRN3 is the first gene with a probable inhibitory effect on GnRH secretion, with mutations identified within humans. To date, MKRN3 is the most common genetic defect associated with CPP. The identification of loss-of-function mutations in this gene can contribute to the diagnosis of CPP, especially in boys in whom the signs of puberty initiation are not easily detectable, thereby helping to make the diagnosis earlier and facilitating treatment decisions. In addition, the presence of MKRN3 mutations can contribute to early diagnosis of CPP in familial cases and guide genetic counseling. It is not clear if there is a sex difference in the effect of MKRN3 mutations, but it

Published by Bioscientifica Ltd 
is evident that mutations in this gene accelerate puberty initiation in both sexes. Although the precise mechanism of regulation of GnRH secretion by MKRN3 is not yet understood, its importance in the hypothalamicpituitary-gonadal axis is indisputable. The studies of Mkrn3 expression in the hypothalamic arcuate nucleus of mice support the findings that loss-of-function mutations in humans lead to early puberty initiation and strengthen the hypothesis that MKRN3 acts as an inhibitor of GnRH secretion during childhood (Fig. 3). Ultimately, the recent GWAS findings linking MKRN3 with the age of menarche have consolidated the involvement of this gene in pubertal timing.

The identification of a putative inhibitory factor in the hypothalamic-pituitary-gonadal axis has opened an exciting new arena in the neuroendocrine field. Further studies will elucidate the precise mechanism of action of this important regulator of GnRH secretion.

\section{Declaration of interest}

The authors declare that there is no conflict of interest that could be perceived as prejudicing the impartiality of this review.

\section{Funding}

This work was supported by FAPESP grant numbers 2013-06391-1 to DBM and 2013-03236-5 to ACL; Eunice Kennedy Shriver NICHD/NIH through cooperative agreement U54HD28138 as part of the Specialized Cooperative Centers Program in Reproduction and Infertility Research and Eunice Kennedy Shriver NICHD/NIH R01HD019938, to UK; and 1F05HD072773-03, to APA.

\section{References}

Abreu AP, Dauber A, Macedo DB, Noel SD, Brito VN, Gill JC, Cukier P, Thompson IR, Navarro VM, Gagliardi PC et al. 2013 Central precocious puberty caused by mutations in the imprinted gene MKRN3. New England Journal of Medicine 368 2467-2475. (doi:10.1056/ NEJMoa1302160)

Barabino SM, Hubner W, Jenny A, Minvielle-Sebastia L \& Keller W 1997 The 30-kD subunit of mammalian cleavage and polyadenylation specificity factor and its yeast homolog are RNA-binding zinc finger proteins. Genes and Development 11 1703-1716. (doi:10.1101/gad.11. 13.1703)

Behrends C \& Harper JW 2011 Constructing and decoding unconventional ubiquitin chains. Nature Structural \& Molecular Biology 18 520-528. (doi:10.1038/nsmb.2066)

Bianco SD \& Kaiser UB 2009 The genetic and molecular basis of idiopathic hypogonadotropic hypogonadism. Nature Reviews. Endocrinology 5 569-576. (doi:10.1038/nrendo.2009.177)

Bielinska B, Blaydes SM, Buiting K, Yang T, Krajewska-Walasek M, Horsthemke B \& Brannan CI 2000 De novo deletions of SNRPN exon 1 in early human and mouse embryos result in a paternal to maternal imprint switch. Nature Genetics 25 74-78. (doi:10.1038/75629)

Bohne A, Darras A, D'Cotta H, Baroiller JF, Galiana-Arnoux D \& Volff JN 2010 The vertebrate makorin ubiquitin ligase gene family has been shaped by large-scale duplication and retroposition from an ancestral gonad-specific, maternal-effect gene. BMC Genomics 11721. (doi:10.1186/1471-2164-11-721)

Bressler J, Tsai TF, Wu MY, Tsai SF, Ramirez MA, Armstrong D \& Beaudet AL 2001 The SNRPN promoter is not required for genomic imprinting of the Prader-Willi/Angelman domain in mice. Nature Genetics $\mathbf{2 8}$ 232-240. (doi:10.1038/90067)

Deshaies RJ \& Joazeiro CA 2009 RING domain E3 ubiquitin ligases. Annual Review of Biochemistry 78 399-434. (doi:10.1146/annurev.biochem.78. 101807.093809)

Elks CE, Perry JR, Sulem P, Chasman DI, Franceschini N, He C, Lunetta KL, Visser JA, Byrne EM, Cousminer DL et al. 2010 Thirty new loci for age at menarche identified by a meta-analysis of genome-wide association studies. Nature Genetics 42 1077-1085. (doi:10.1038/ng.714)

Gray TA, Hernandez L, Carey AH, Schaldach MA, Smithwick MJ, Rus K, Marshall Graves JA, Stewart CL \& Nicholls RD 2000 The ancient source of a distinct gene family encoding proteins featuring RING and $\mathrm{C}(3) \mathrm{H}$ zinc-finger motifs with abundant expression in developing brain and nervous system. Genomics 66 76-86. (doi:10.1006/geno. 2000.6199)

He C, Kraft P, Chen C, Buring JE, Pare G, Hankinson SE, Chanock SJ, Ridker PM, Hunter DJ \& Chasman DI 2009 Genome-wide association studies identify loci associated with age at menarche and age at natural menopause. Nature Genetics 41 724-728. (doi:10.1038/ng.385)

Herman-Giddens ME, Slora EJ, Wasserman RC, Bourdony CJ, Bhapkar MV, Koch GG \& Hasemeier CM 1997 Secondary sexual characteristics and menses in young girls seen in office practice: a study from the Pediatric Research in Office Settings network. Pediatrics 99 505-512. (doi:10.1542/peds.99.4.505)

Hershko A \& Ciechanover A 1998 The ubiquitin system. Annual Review of Biochemistry 67 425-479. (doi:10.1146/annurev.biochem.67.1.425)

Hershko A, Razin A \& Shemer R 1999 Imprinted methylation and its effect on expression of the mouse Zfp127 gene. Gene 234 323-327. (doi:10.1016/S0378-1119(99)00192-4)

Hudson BP, Martinez-Yamout MA, Dyson HJ \& Wright PE 2004 Recognition of the mRNA AU-rich element by the zinc finger domain of TIS11d. Nature Structural \& Molecular Biology 11 257-264. (doi:10.1038/ nsmb738)

Hughes IA 2013 Releasing the brake on puberty. New England Journal of Medicine 368 2513-2515. (doi:10.1056/NEJMe1306743)

Jong MT, Gray TA, Ji Y, Glenn CC, Saitoh S, Driscoll DJ \& Nicholls RD $1999 a$ A novel imprinted gene, encoding a RING zinc-finger protein, and overlapping antisense transcript in the Prader-Willi syndrome critical region. Human Molecular Genetics 8 783-793. (doi:10.1093/hmg/ 8.5.783)

Jong MT, Carey AH, Caldwell KA, Lau MH, Handel MA, Driscoll DJ, Stewart CL, Rinchik EM \& Nicholls RD $1999 b$ Imprinting of a RING zinc-finger encoding gene in the mouse chromosome region homologous to the Prader-Willi syndrome genetic region. Human Molecular Genetics 8 795-803. (doi:10.1093/hmg/8.5.795)

Kanber D, Giltay J, Wieczorek D, Zogel C, Hochstenbach R, Caliebe A, Kuechler A, Horsthemke B \& Buiting K 2009 A paternal deletion of MKRN3, MAGEL2 and NDN does not result in Prader-Willi syndrome. European Journal of Human Genetics 17 582-590. (doi:10.1038/ejhg. 2008.232)

Kim JH, Park SM, Kang MR, Oh SY, Lee TH, Muller MT \& Chung IK 2005 Ubiquitin ligase MKRN1 modulates telomere length homeostasis through a proteolysis of hTERT. Genes and Development 19 776-781. (doi:10.1101/gad.1289405)

Kim JH, Park KW, Lee EW, Jang WS, Seo J, Shin S, Hwang KA \& Song J 2014 Suppression of PPAR $\gamma$ through MKRN1-mediated ubiquitination and degradation prevents adipocyte differentiation. Cell Death and Differentiation 21 594-603. (doi:10.1038/cdd.2013.181)

Kvale G 1992 Reproductive factors in breast cancer epidemiology. Acta Oncologica 31 187-194. (doi:10.3109/02841869209088901) 
Lakshman R, Forouhi NG, Sharp SJ, Luben R, Bingham SA, Khaw KT, Wareham NJ \& Ong KK 2009 Early age at menarche associated with cardiovascular disease and mortality. Journal of Clinical Endocrinology and Metabolism 94 4953-4960. (doi:10.1210/jc.2009-1789)

Lalande M 1996 Parental imprinting and human disease. Annual Review of Genetics 30 173-195. (doi:10.1146/annurev.genet.30.1.173)

Lee EW, Lee MS, Camus S, Ghim J, Yang MR, Oh W, Ha NC, Lane DP \& Song J 2009 Differential regulation of p53 and p21 by MKRN1 E3 ligase controls cell cycle arrest and apoptosis. EMBO Journal 28 2100-2113. (doi:10.1038/emboj.2009.164)

Macedo DB, Abreu AP, Reis AC, Montenegro LR, Dauber A, Beneduzzi D, Cukier P, Silveira LF, Teles MG, Carroll RS et al. 2014 Central precocious puberty that appears to be sporadic caused by paternally inherited mutations in the imprinted gene makorin ring finger 3. Journal of Clinical Endocrinology and Metabolism 99 E1097-E1103. (doi:10.1210/ jc.2013-3126)

Murray MV, Turnage MA, Williamson KJ, Steinhauer WR \& Searles LL 1997 The Drosophila suppressor of sable protein binds to RNA and associates with a subset of polytene chromosome bands. Molecular and Cellular Biology 17 2291-2300.

Navarro VM, Gottsch ML, Wu M, Garcia-Galiano D, Hobbs SJ, Bosch MA, Pinilla L, Clifton DK, Dearth A, Ronnekleiv OK et al. 2011 Regulation of NKB pathways and their roles in the control of Kiss1 neurons in the arcuate nucleus of the male mouse. Endocrinology 152 4265-4275. (doi:10.1210/en.2011-1143)

Nicholls RD, Saitoh S \& Horsthemke B 1998 Imprinting in Prader-Willi and Angelman syndromes. Trends in Genetics 14 194-200. (doi:10.1016/ S0168-9525(98)01432-2)

Ohta T, Buiting K, Kokkonen H, McCandless S, Heeger S, Leisti H, Driscoll DJ, Cassidy SB, Horsthemke B \& Nicholls RD 1999 Molecular mechanism of angelman syndrome in two large families involves an imprinting mutation. American Journal of Human Genetics 64 385-396. (doi:10.1086/302232)

Ojeda SR \& Lomniczi A 2014 Puberty in 2013: unravelling the mystery of puberty. Nature Reviews. Endocrinology 10 67-69. (doi:10.1038/nrendo. 2013.233)

Omwancha J, Zhou XF, Chen SY, Baslan T, Fisher CJ, Zheng Z, Cai C \& Shemshedini L 2006 Makorin RING finger protein 1 (MKRN1) has negative and positive effects on RNA polymerase II-dependent transcription. Endocrine 29 363-373. (doi:10.1385/ENDO:29:2:363)

Perry JR, Day F, Elks CE, Sulem P, Thompson DJ, Ferreira T, He C, Chasman DI, Esko T, Thorleifsson G et al. 2014 Parent-of-originspecific allelic associations among 106 genomic loci for age at menarche. Nature 514 92-97. (doi:10.1038/nature13545)

Rabinovitz S, Kaufman Y, Ludwig G, Razin A \& Shemer R 2012 Mechanisms of activation of the paternally expressed genes by the Prader-Willi imprinting center in the Prader-Willi/Angelman syndromes domains. PNAS 109 7403-7408. (doi:10.1073/pnas.1116661109)

Rapkins RW, Hore T, Smithwick M, Ager E, Pask AJ, Renfree MB, Kohn M, Hameister H, Nicholls RD, Deakin JE et al. 2006 Recent assembly of an imprinted domain from non-imprinted components. PLoS Genetics 2 e182. (doi:10.1371/journal.pgen.0020182)

Rodriguez-Jato S, Nicholls RD, Driscoll DJ \& Yang TP 2005 Characterization of cis- and trans-acting elements in the imprinted human SNURFSNRPN locus. Nucleic Acids Research 33 4740-4753. (doi:10.1093/nar/ gki786)

Schreiner F, Gohlke B, Hamm M, Korsch E \& Woelfle J 2014 MKRN3 mutations in familial central precocious puberty. Hormone Research in Paediatrics 82 122-126. (doi:10.1159/ 000362815)

Schwabe JW \& Klug A 1994 Zinc mining for protein domains. Nature Structural Biology 1 345-349. (doi:10.1038/nsb0694-345)

Semple RK \& Topaloglu AK 2010 The recent genetics of hypogonadotrophic hypogonadism - novel insights and new questions. Clinical Endocrinology 72 427-435. (doi:10.1111/j.1365-2265.2009. 03687.x)

Settas N, Dacou-Voutetakis C, Karantza M, Kanaka-Gantenbein C, Chrousos GP \& Voutetakis A 2014 Central precocious puberty in a girl and early puberty in her brother caused by a novel mutation in the MKRN3 gene. Journal of Clinical Endocrinology and Metabolism 99 E647-E651. (doi:10.1210/jc.2013-4084)

Shemer R, Hershko AY, Perk J, Mostoslavsky R, Tsuberi B, Cedar H, Buiting K \& Razin A 2000 The imprinting box of the Prader-Willi/Angelman syndrome domain. Nature Genetics 26 440-443. (doi:10.1038/82571)

Silveira LG, Noel SD, Silveira-Neto AP, Abreu AP, Brito VN, Santos MG Bianco SD, Kuohung W, Xu S, Gryngarten M et al. 2010 Mutations of the KISS1 gene in disorders of puberty. Journal of Clinical Endocrinology and Metabolism 95 2276-2280. (doi:10.1210/jc.2009-2421)

Teles MG, Bianco SD, Brito VN, Trarbach EB, Kuohung W, Xu S, Seminara SB, Mendonca BB, Kaiser UB \& Latronico AC 2008 A GPR54-activating mutation in a patient with central precocious puberty. New England Journal of Medicine 358 709-715. (doi:10.1056/NEJMoa073443)

de Vries L, Gat-Yablonski G, Dror N, Singer A \& Phillip M 2014 A novel MKRN3 missense mutation causing familial precocious puberty. Human Reproduction 29 2838-2843. (doi:10.1093/humrep/deu256)

Yang PH, Cheung WK, Peng Y, He ML, Wu GQ, Xie D, Jiang BH, Huang QH, Chen Z, Lin MC et al. 2008 Makorin-2 is a neurogenesis inhibitor downstream of phosphatidylinositol 3-kinase/Akt (PI3K/Akt) signal. Journal of Biological Chemistry 283 8486-8495. (doi:10.1074/jbc. M704768200)

Zacharias L \& Wurtman RJ 1969 Age at menarche. Genetic and environmental influences. New England Journal of Medicine $\mathbf{2 8 0}$ 868-875. (doi:10.1056/NEJM196904172801606)

Received in final form 10 February 2015

Accepted 6 March 2015 http://jme.endocrinology-journals.org

DOI: 10.1530/JME-14-0315
(C) 2015 Society for Endocrinology Printed in Great Britain
Published by Bioscientifica Ltd 